\title{
ANIMMA 2021
}

\section{June 21-25, 2021, Prague, Czech Republic}

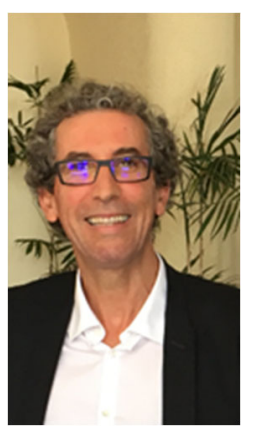

Dear colleagues and friends,

The conference on Advancements in Nuclear Instrumentation Measurement Methods and their Applications ANIMMA has always strived to create a special meeting place shared by all those working in nuclear instrumentation and its applications, as we strongly believe that cross-border exchanges between scientists, engineers and industrialists can only lead to the most developed ideas, the best solutions and the most efficient collaborations and partnerships. ANIMMA continues to maintain a high level of scientific and technical quality by presenting not only the latest advances but also the state of the art in each field through the participation of international specialists and experts.

Since the beginning of 2020, travelling around the world to attend meetings, congresses, symposia, and conferences is highly handicapped by the Covid-19 pandemic whose development differs from place to place and time to time. Teleworking, virtual meetings, distance courses are used as substitutes for the traditional face to face meetings, with an inevitable loss of quality of the human contacts which are believed to be of paramount importance to build enthusiasm for a project, an idea, a collaboration, a grouping of individuals.

In such a context, the ANIMMA2021 committees (Program, Organizing and Steering committees), by following the sanitary rules as well as the Czech government recommendations, dedicated best and huge efforts in designing the Conference in hybrid layout to make it highly attractive and very efficient for both the on-site participants as well as the remote ones.

Therefore the best possible communication means gave the opportunity not only to remotely follow or deliver presentations, but also to interact online in the best possible way with the authors and contributors as well as the exhibitors, with the other connected experts, and to access recorded materials in delayed mode to cope with the time-zone differences. This required also a fully committed and flexible conference management team to create a conference that is rewarding for both presenters and attendees.

ANIMMA-2021 was held from June $21^{\text {st }}-25^{\text {th }}$ in hybrid mode at Clarion Congress Hotel in Prague, Czech Republic. The conference was locally organized by the Czech Technical University represented by the institute of experimental and applied physics (IEAP) in a strong partnership with CEA (France), SCK-CEN (Belgium), Aix-Marseille University (France), Josef Stefan Institute (Slovenia). The ANIMMA2021 was technically sponsored by IEEE/NPSS 


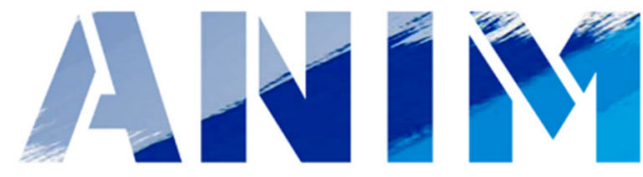

Prague, Czech Republic

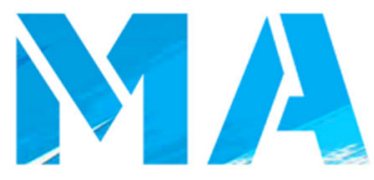

Hybrid mode

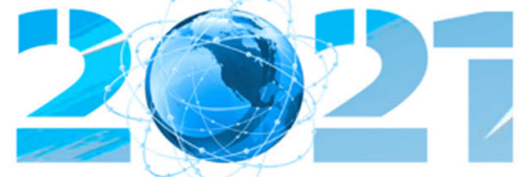

June 21-25, 2021

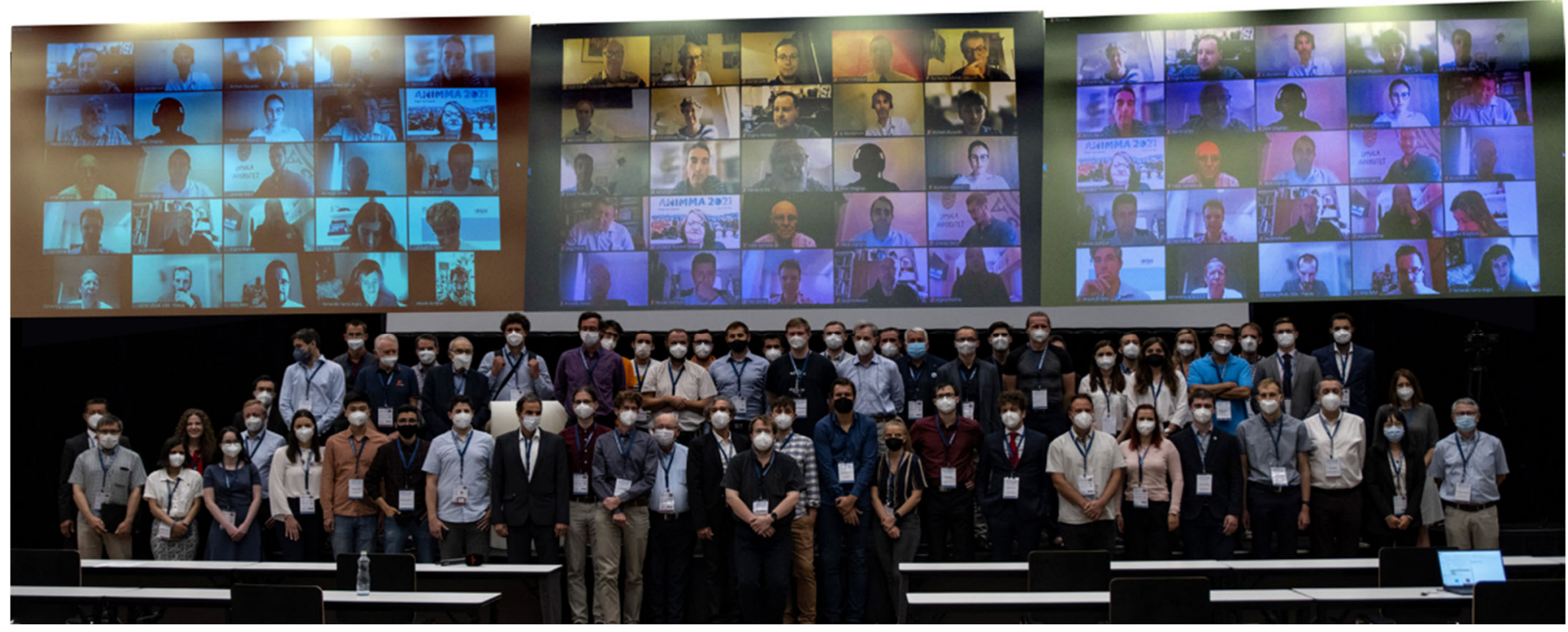

The conference program was dealing with:

- 2 full-day short-courses: The classical lectures have been partly given on-site, partly via remote connection. They have been streamed to all students simultaneously via a Zoom meeting, allowing for interaction between students and lecturers. The practical sessions have been performed by IEAP and CAEN. A part of exercises was in remote mode, simultaneously for the students on-site and those remotely connected and the other part as a real hands-on course for the students on-site. Separately a remote interactive demonstration session has been organized for the remotely connected students. Participants to the Short Courses had the opportunity to perform immediately after the courses a multiple choice test (35 multiplechoice questions on all courses).

- 3 international workshops: The topics of the workshops addressed in this 7th ANIMMA edition focused on instrumentation for major research facilities in fusion and fission fields, crystalline materials for radiation detection in harsh media and prospective technologies for the future of nuclear medicine. 19 speakers and 71 people participated from 22 countries. Each workshop included time slots for discussion and exchange between speakers, experts and participants. These periods were useful to share opinions, cross-fertilize skills and expertise and identify collaborative research axes to go further by solving scientific and technological challenges.

- 3 prestigious keynote lecturers :

- Dr. William D. MAGWOOD, IV, Director-General, OECD Nuclear Energy Agency (NEA) on "Nuclear Solutions: Innovation for an Energy Transition"

- Dr. Alan OWENS, European Space Agency, ESTEC and IEAP on "Recent developments in sensor materials".

- Prof. Dr. Katia PARODI, Ludwig-Maximilians-Universität München, Department of Experimental Medical Physics on "Getting to the point in particle therapy" 
- 4 plenary sessions in a new transversal topic on "current trends in development of radiation detectors",

- A second new topic on "Space sciences and technology".

- Over 270 contributions presented in 31 parallel oral sessions

- A permanent poster session

ANIMMA-2021 welcomed 320 attendees from 29 nationalities including 65 graduated students. 30\% of the attendees participated physically and $70 \%$ attended remotely.

The ANIMMA2021 attendees deserve our warmest thanks and consideration for making this seventh edition an exceptional success in extraordinary situation.

All the committee members are looking forward to welcoming everyone again at the ANIMMA2023 in Pisa and Viareggio in Tuscany, Italy on June 12-16, 2023.

\section{Prof. Dr. Abdallah LYOUSSI}

ANIMMA General Chairman and Program Committee Chair

(*) Advancements in Nuclear Instrumentation Measurement Methods and their Applications 